\title{
An empirical investigation of opportunistic behaviour in project networks and its impact on market efficiency
}

\author{
HAKAN I. UNSAL and JOHN E. TAYLOR* \\ Department of Civil Engineering and Engineering Mechanics, Columbia University, 618 S. W. Mudd Bldg., 500 West \\ 120th Street, New York, NY 10027, USA
}

Received 6 February 2011; accepted 18 February 2011

\begin{abstract}
Subcontractor selection strategies employed by contractors can significantly impact the success of individual organizations and the overall efficiency of the market. Long-term partnerships are promoted by experts from both academia and industry as a means of achieving improved project network productivity; however, opportunistic bidding behaviour that may accompany its implementation might negate the benefits of close collaboration. We conducted a bidding experiment to empirically investigate whether opportunistic behaviour would emerge in a simulated subcontracting process. We conducted 18 experiments involving 6947 competitive bidding transactions between contractors and a pool of subcontractors. The empirical data were collected through an Internet-based interactive bidding simulation developed by the investigators. The findings contribute an empirical demonstration of how opportunistic behaviour occurs in the bidding process and how it can lead to different partner selection strategies by contractors and different market outcomes in terms of efficiency.
\end{abstract}

Keywords: Bidding, game theory, hold-up problem, market efficiency, opportunistic behaviour, project networks.

\section{Introduction}

Research has linked subcontracting strategy to improved performance and faster innovation adaptation (Holt, 1998; Kumaraswamy and Matthews, 2000). Researchers have suggested that through a collaborative contracting approach, firms can minimize their transaction costs and maximize inter-organizational learning which will lead to higher productivity. In the 1990s, this approach was investigated exhaustively under the term 'partnering' (Chan et al., 2004). During this time period, a Construction Industry Institute (CII) report presented the benefits of and the barriers to partnering (CII, 1991). Several case studies also found that partnering improved firm productivity and innovative capacity (Barlow, 2000; DeVilbiss and Leonard, 2000). Partnering can refer either to a project partnership where companies form an alliance for the duration of the project, or to a long-term partnership where companies agree to work together through several projects. The focus of this paper is long-term partnerships, as these partnerships have an impact on the structure and efficiency of the industry overall.

A recent simulation study demonstrated that in a more relationally stable environment where firms subcontract from fewer firms, inter-organizational project networks adapt to changes faster, therefore, can realize the benefits of the innovation sooner (Taylor et al., 2009). There appears to be a continuum where at one extreme is the pure market transaction where subcontractors are selected from a large pool with equal preference for any given subcontractor and at the other extreme is the long-term partnership where contractors stick to the same partners across multiple projects. The argument made by Taylor et al. (2009) would suggest that project networks get more efficient as they become more relationally stable. However, despite the benefits of long-term partnerships, the bidding process has not been eliminated in favour of long-term partnering strategies. One cause may be related to a fear of opportunistic behaviour that may occur if a contractor becomes dependent on specific subcontractors over

*Author for correspondence. E-mail: taylor@civil.columbia.edu 
the course of a long-term collaboration. The CII report (1991, p. 6) on partnering also supports this argument: 'Dependency is a natural consequence of long-term commitment'. The report suggests minimizing these challenges by working with more than one partner. In this paper, first we seek to ascertain whether opportunistic behaviour will emerge in a simulated project network over repeated bidding interactions and second, to examine the impact such behaviour may have on overall market efficiency.

An expectation of synergy which will improve interactional efficiency is a key expected benefit of collaboration whether it is teamwork with individuals or a joint venture alliance between organizations. However, the question of how the returns from the resulting synergy will be distributed fairly can complicate the process. One idealistic option would be to distribute the returns based on objective criteria which reflect the relative effort. However, the conditions of the problem might not allow such practice. The incentive for firms to take advantage of the situation in the absence of monitoring can create a barrier for collaboration. In this paper, we are interested in understanding whether a similar problem exists in long-term partnerships between contractors and subcontractors in architecture, engineering and construction $(\mathrm{A} / \mathrm{E} / \mathrm{C})$ project networks.

\section{Background}

\section{Opportunistic behaviour}

The concept of opportunism in inter-organizational interactions originated from the work of Williamson (1975) and has since been central to discussions of inter-organizational collaboration. Strategy researchers adopt a transaction cost economics perspective to demonstrate the existence of opportunistic behaviour potential in different industries, how it impacts the outcome of collaboration or the managerial decision making of the parties involved (Provan and Skinner, 1989). Williamson (1975, p. 9) distinguishes opportunism from hyper-rationality as the hyper-rational 'economic man' is self-interest seeking, whereas, opportunistic behaviour is 'self-interest seeking with guile'. Organizations are vulnerable to opportunistic behaviour for two reasons. The bounded rationality of the agents combined with an uncertain future makes it impossible to write complete contracts that will cover every contingency. However, uncertainty by itself would not be a problem if the resolution of the conflicts between parties was not costly. Firms would adapt the contract to the changing conditions and requirements of the transaction and eliminate asymmetric bargaining power. The cost of using the legal system to arbitrate disputes creates a zone for parties where they can take advantage of the situation.

Opportunistic behaviour in the context of project networks drew attention from construction researchers as well. Chang and Ive (2007a) focused on the bargaining power that the contractor has over the client after project initiation and discussed the opportunistic behaviour potential that emerges as the design is modified throughout the project. If the client wants to discontinue working with a contractor in case of any dispute, then they are left with two options: terminate the project and try to get a salvage value out of the completed portion or switch the contractor. Either of these two options is costly which gives the contractor bargaining power. Researchers have examined the effect of opportunistic bidding behaviour in construction markets (Ho and Liu, 2004; Lo et al., 2007). They mainly focused on the fact that the contractors submit abnormally low bids and try to increase their margin through cutting corners or finding loopholes in the contract in order to charge more for change orders. The enabler of the opportunistic behaviour for both examples is the post-contractual dependency of the client on the contractor.

\section{Hold-up in repetitive projects}

Dependency between firms is caused by asset specific investments which, by definition, lose value significantly if not usable for their intended purpose (Williamson, 1975). The asymmetric bargaining power caused by the asset-specific investment will create what the transaction cost economics literature refers to as the 'hold-up problem' (Goldberg, 1976; Klein et al., 1978). A typical example of the hold-up problem is given from the manufacturing industry. In the classical scenario the buyer (firm A) asks a supplier (firm B) to make an investment that is specific to the needs of the buyer. If this investment has significantly lower salvage value outside that transaction, then firm A will have a bargaining power as a result of this investment. Some researchers suggest self-enforcing contractual remedies for avoiding the threat, hence providing a possible mechanism for more effective collaboration (Rogerson, 1992; Noldeke and Schmidt, 1995). Aghion et al. (1994) posited that risk can be shared if ex post renegotiation is reflected in the initial contract. Investment decisions can also affect the magnitude of the hold-up threat. Some researchers have suggested gradual investment to overcome incomplete contracts that may lead to hold-up (Pitchford and Snyder, 2004).

The same problem can occur in construction during the project when the contractor has a high cost associated with switching subcontractors. In a case study of the Chunnel project, Chang and Ive (2007b) 
demonstrated the existence of the hold-up problem in the presence of process specificity. Construction researchers have recognized the significance of interfirm dependency and the resultant hold-up problem within a single contractual agreement. However, dependency and the potential of hold-up might arise in a longterm collaboration where repetitive transactions occur. By the long-term collaboration, we refer to the quasifirm governance structure defined by Eccles (1981) where the buyer purchases the service from a limited pool of suppliers as opposed to the committed partnership where the competition between suppliers is minimized. In a single transaction, the hold-up problem is an incentive for integration (Castaneda, 2006) because it will improve the organization of production, whereas, in repetitive transactions it may change the structure and, hence, the efficiency of the interorganizational network. One possible reason for the lack of attention on hold-up across repetitive transactions in the literature may be that, in repetitive transactions, it is believed that there is no asset-specific investment. Once a project is closed out the transaction is complete and the investments are fully exhausted. Hiring another subcontractor in the next project is not considered as switching since there is no promise to continue collaborating across multiple projects. This neglects the impact of inter-organizational learning.

Part of the synergy created in a project is specific to the contractor-subcontractor interaction and cannot be carried forward to the next transaction with another subcontractor. This is one of the reasons why close inter-organizational cooperation is suggested by experts and academicians (e.g. Miozzo and Dewick, 2004). Continuous collaboration between firms across projects will minimize transaction costs and maximize the inter-organizational learning benefits. Firms prefer to work with a subcontractor with whom they have experience not only because of the reputation affect, but also because it will be less costly and risky (Miozzo and Dewick, 2004). However, the potential economic benefit that the client can receive if they contract with the same subcontractor in the next project is also the opportunity cost of not working with the same subcontractor if the contractor decides to hire a different subcontractor. This creates a cost to switch from one subcontractor to another in between two transactions. As a result of working with the same subcontractor for several projects, the client can inadvertently give the subcontractor bargaining power during the bidding process. Therefore another form of asset specificity and relational specificity can exist.

Another reason the hold-up problem in repetitive transactions may not have attracted attention by researchers is a belief that competitive market pressure on the subcontractor eliminates opportunistic behaviour. Contractors are on the short side of the market which makes the industry highly competitive. Also, since the contractor has multiple decision points where they have the right to choose from a pool of subcontractors, the assumption is that the contractor can switch before any project without sacrificing profit. Therefore, the subcontractor has to satisfy the contractor in order to guarantee future work which gives the bargaining power back to the contractor. In the manufacturing industry the assumption that the subcontractor is sole price-taker would be correct. However, construction transactions have unique dynamics due to the nature of the industry. Each construction project is unique which eliminates the effect of the price mechanism significantly. The only price information the contractor has about the service they are intending to procure from a subcontractor is the bids received. There is a cost associated if contractors want to increase the accuracy of the information about the value of the service they are buying. Therefore, in a pool where there are limited suppliers, the subcontractor will feel the pressure of the market less since the contractor will not be able to compare their price to a 'market price'. This is one of the reasons why Eccles (1981) found that, in the construction industry, the contractors make subcontracting decisions based on a combination of relationships and price.

If a contractor can give the subcontractor an advantage by making relation-specific investments and the competition can be limited, then if a contractor can switch in between projects, would the contractor be still vulnerable to the hold-up problem caused by the opportunistic behaviour by the subcontractor? It has been demonstrated analytically through an integration of game theory modelling and agent-based simulation that the subcontractor selection decision made by a contractor may have an adverse impact on revenue if the potential for hold-up is disregarded (Unsal and Taylor, 2011). If there is a benefit to continuous collaboration, then the subcontractor might recognize there is a switching cost to the contractor and adjust his or her profit margin accordingly. The simulation only serves as an algebraic proof of the existence of the hold-up potential. In order to argue its existence and impact on the market, an empirical investigation is needed. In this paper, we replicate a market in an interactive bidding game. We conducted 18 experiments involving 38 human subjects who interact in a total of 6947 competitive bidding interactions. The first objective of this empirical study was to observe whether opportunistic behaviour exists in repetitive transactions if there is an incentive for continuous collaboration. Therefore, we hypothesized that as collaboration costs decrease, subcontractors would increase their bid price. We formally state the hypothesis as follows: 
Hypothesis 1:The average winning subcontractor bid price in a market of contractors and subcontractors will have an increasing trend as collaboration costs decrease.

If we are able to identify an increasing trend in terms of price, then this would provide evidence that subcontractors behaved opportunistically to capture more of the collaboration benefits for themselves. A second objective of the study was to examine whether opportunistic behaviour - if it exists-impacts the overall efficiency of the market over time. Therefore, after testing the hypothesis, we examine the macro-level effects of opportunistic behaviour on the efficiency of the market.

\section{Methodology}

We developed an interactive bidding game to create an artificial market. We chose to collect empirical data in an experiment for two reasons. First, researchers of behavioural game theory have found that decisions of individuals deviate from that predicted by the Nash equilibrium (Henrich, 2000). Nash equilibrium is defined as the point at which none of the players can be better off by changing their strategies (Nash, 1951). Therefore, an experimental study with human subjects has stronger validity than a simulation of individuals where each agent is assumed to be identical, behave rationally and have unlimited computational capacity. In fact, analytical game theory is often criticized because people do not think with equations and are not capable of making many iterations (Mailath, 1998). The Nash equilibrium is an equilibrium point which agents reach by thinking iteratively. Even though people are only capable of limited iteration in a single game, they do approach the Nash equilibrium when the game is repeated (Camerer, 2003). We designed the experiment as a repeated game so that individuals receive feedback from the behaviour of the group and are able to update their strategies. For this reason, we also encouraged participants to participate in multiple experiments. This not only compensated for the limited iterative thinking but also allowed us to observe how the market evolved over time as participants became more experienced.

\section{Data collection}

In this experiment, participants were recruited in the online workplace website Amazon Mechanical Turk (AMT). AMT has registered users all over the world completing tasks that employers submit. The assignments usually consist of subtasks that require human intelligence that computer programs are unable to complete. AMT has begun to be used for research purposes as well (Kittur et al., 2008). It allows researchers to collect data from a specific demographic profile in a certain geographical region. We recruited AMT users to participate in an interactive bidding game. The participants were required to reside in the USA. We did not require that participants have experience with bidding or working in the architecture, engineering and construction industry. The rationale for this was that one goal of the study was to observe the evolution of the market over time. Participants with related working experience would be predisposed to specific bidding strategies, would do several iterations in terms of bidding strategy evolution in a single game and, as such, we would not be able to observe how the market evolves. The market would already be effectively approaching the Nash Equilibrium. How participants with no engineering background or bidding experience learn by receiving feedback from the market is discussed in more detail in the results section.

Participants were directed to an interactive bidding experiment website and were asked to enter the bidding experiment virtual room and wait until the experiment started. Hypertext preprocessor (PHP) and MySQL web programming languages were used to develop the interactive online environment. MySQL was used to keep track of the strategy data. User inputs were stored in tables and accessed using PHP when needed. The bidding experiments were executed in real time in which all participant user interfaces were updated simultaneously to allow users to access relevant data about projects and other participants.

Each of the 18 online interactive bidding sessions conducted had the capacity to hold 25 participants, which included 15 assigned to the role of subcontractors and the remaining participants assigned to the role of contractors. Each participant was compensated with a pre-established sum of money plus a bonus which was calculated based on their earnings in the experiment. This compensation strategy was employed to increase the motivation of the players to succeed in the game. At the end of each experiment session, the participants were asked to respond to a short questionnaire describing their strategy. Each of the 18 experiment sessions took approximately 90 minutes to complete. We ran approximately one experiment per day over a period of several weeks to collect the experimental data.

\section{Experimental design}

Each participant was assigned one of two roles: contractor (bid-taker) or subcontractor (bid-submitter). Each experiment session was comprised of 10 successive projects. For each project there were three stages. In the first stage, the contractors requested bids from the 
subcontractors. In the second stage, the subcontractors responded to the bid requests by submitting a bid price. In the third stage, the contractors awarded projects to subcontractors. Each role had a unique objective function and cost structure. To ensure the motivation of the participants, the participants were compensated based on their relative financial success in the experiment compared with the other participants.

\section{Contractors}

For each of the 10 projects in each experiment session, contractors completed projects to earn $\$ 200000$ in revenue. The 10 projects were assumed to be identical so the revenue was constant for each project throughout the experiment. The objective of the contractors was to maximize their profit by minimizing their cost. The following equation represents the objective function of the contractor role:

$$
\operatorname{Max} \pi=\sum_{\mathrm{i}=1}^{10}\left(200,000-\mathrm{TCc}_{\mathrm{i}}-\mathrm{p}_{\mathrm{i}}\right),
$$

where $\pi$ is the total profit; $\mathrm{TCc}_{\mathrm{i}}$ the total transaction costs for the contractor in period $i$; $p_{i}$ the winning price of the period $i$.

The total transaction cost $\left(\mathrm{TCc}_{\mathrm{i}}\right)$ is the sum of three different types of transaction costs. One of the reasons why firms do not keep their pool of potential subcontractors infinitely large is that there is a cost associated with collecting and evaluating bids. There are also long-term costs of working with a large pool of suppliers. To represent these two factors, two transaction costs are used in the experiment. Every time a contractor requests a bid and every time they evaluate a bid, the transaction costs of 'bid request cost' and 'bid evaluation cost' apply, respectively. We assumed the cost of a single bid request to be US $\$ 1000$ and the cost of a single bid evaluation to be US\$3000. A third type of transaction cost for the contractor represents the interorganizational learning benefits. Firms decrease their transaction costs that are associated with the collaboration as they gain experience working with each other. They create more effective solution methods to problems by developing inter-organizational routines, resolving conflicts more efficiently and decreasing monitoring costs. Also, as the partners become more familiar with each other the potential risk goes down. The collaboration cost follows the learning curve function as defined in the following equation:

$$
\mathrm{CC}_{\mathrm{c}, \mathrm{s}}=\mathrm{CC}_{0} \times\left(\mathrm{n}_{\mathrm{c}, \mathrm{s}}\right)^{\log _{2} \lambda}
$$

where $\mathrm{CC}_{0}$ boundary cost of working with any firm for the first time; $\mathrm{CC}_{\mathrm{c}, \mathrm{s}}=$ boundary cost of contractor, $c$, when they work with subcontractor, $s ; \mathrm{n}_{\mathrm{C}, \mathrm{S}}=$ number of projects that contractor, $c$, worked with subcontractor, $s ; \lambda=$ learning rate.

Contractors were asked to maximize their profits and given an incentive to do so since their compensation for participating in the experiment was based on their profits earned in the experiment.

\section{Subcontractors}

Subcontractors competed with each other by submitting bids to contractors. Their objective function was to maximize their profit by both minimizing cost and maximizing revenue. For any subcontractor, $s$, the objective function was:

$$
\operatorname{Max} \pi=\sum_{\mathrm{i}=1}^{10}\left[\sum_{\mathrm{c}=1}^{\mathrm{c}}\left(\mathrm{p}_{\mathrm{c}, \mathrm{i}}-\mathrm{c}_{\mathrm{c}, \mathrm{i}}\right) \times \mathrm{I}_{\mathrm{c}}(\text { winning })\right]-\mathrm{TCs}_{\mathrm{i}}
$$

where, $\pi$ is the total profit; $p_{c, i}$ the price that the subcontractor sent to contractor, $c$, in $\mathrm{i}^{\text {th }}$ period; $\mathrm{C}_{\mathrm{c}, \mathrm{i}}$ the cost of the subcontractor if they get the project from contractor, $c$ in $\mathrm{i}^{\text {th }}$ period; $\mathrm{I}_{\mathrm{c}}$ (winning) the indicator that shows whether the contractor, $c$ awarded the bid to the [subcontractor 1 for being awarded the bid, 0 for not being awarded the bid]; $\mathrm{TCs}_{\mathrm{i}}=$ the transaction cost of the subcontractor in period, $i$.

The transaction cost for the subcontractor is the cost they spend on preparing the bid. Subcontractors will send bids as long as they think their bids are being seriously considered. If a contractor does not hire a subcontractor for several projects, the subcontractor may stop submitting bids to that contractor. This impacts the influence of the price mechanism in contractor-subcontractor bidding. A buyer cannot cost effectively get price information by requesting bids from every subcontractor. The transaction cost that represents this factor in the experiment is 'bid preparation cost' which is applied if the subcontractor decides to submit a bid to a contractor. The subcontractors can submit a bid even if one is not requested from them but then they have to compensate the contractor for their bid request and bid evaluation costs. This allows subcontractors to enter the competition without changing the total transaction cost spent.

Assuming the contract is lump sum, a subcontractor's profit is the difference between the revenue and their costs on the project. The cost is estimated based on the material and labour the subcontractor will expend on the tasks. To represent the fluctuations in cost estimation between subcontractors, the cost of the work for the subcontractor is determined randomly between $\$ 80000$ and $\$ 100000$. The subcontractors then take 
into account their own cost values and the uncertainty about their opponent subcontractors' cost values when bidding. Subcontractors were allowed to bid below cost. However, they start with a set amount of money in their bank account and if the bank account goes below zero during the game, they go bankrupt and are not allowed to continue. Information on the previous winners of each project and the collaboration costs are shared with all subcontractors and contractors to emulate a lump sum open bid setting.

\section{Results}

As contractors gained experience with specific subcontractors their collaboration costs decreased. This made the cost of subcontractors with experience working with a specific contractor comparatively lower than other subcontractors. However, the fact that collaboration cost of a specific subcontractor will decrease with experience does not necessarily imply that the average collaboration cost of the winning subcontractors will also decrease. In order for this to occur, the contractors must invest in a small pool of subcontractors and increase their experience with them. The smaller the pool gets, the faster the collaboration cost decreases. Figure 1 shows the average collaboration cost of each of 10 projects and in each of the 18 experiment sessions we conducted. Each data point represents the average collaboration cost of the winning subcontractors in the market for each project. The average of those averages is included as a line in the graph to illustrate the downward trend in collaboration cost over time.

The first objective of this research was to examine whether opportunistic behaviour emerged as one or a few subcontractors gain a productivity advantage compared with their rivals. Although opportunistic behaviour can emerge as decreased quality, in this experiment we anticipated that it might lead to higher prices for winning bids. Figure 2 includes the winning bid price of 18 experiment sessions for each of the 10 simulated projects. The solid line represents the average of the winning bid price for each project for each of the 18 sessions. In the beginning of the collaboration, the average winning bid was very close to the expected cost of the subcontractors which is $\$ 90000$. However, it increased over time and by the 10th project reached a value $22 \%$ higher than the average winning bid in the first project.

Showing that the price is higher in 10th project compared with initial project is not sufficient to prove that the price has an upward trend. Therefore, we employed a one-sided $t$-test to compare price data in different projects. We compared the price data of each project with the price data three projects forward. We assumed that a three-period lag is sufficient to eliminate the effect of local fluctuations in price. One extreme would be to use a one-period lag but that is too short to observe the price increase. The other extreme is to use 10-period lag which sacrifices the validity of the study since it only provides the comparison of the 1st and 10th project. The three-period lag provides seven comparisons and the $p$-values associated with those tests are presented in Table 1.

Table 1 shows that the $p$ values are consistently lower than 0.05 which implies that the price constantly increases. This is also observable in the continuously increasing average bid price plotted in Figure 2. Therefore, Hypothesis 1 is supported. The relationship between the collaboration cost and the average price as related to the hold-up problem is discussed in the next section.

The second objective of this study was to observe how efficiency of the market evolves over time as a result of subcontractor selection strategies. Drawing upon Williamson's (1975) analogy that transaction costs are akin to the friction in mechanical systems, we considered the efficiency of the market as the total transaction costs on each project. Figure 3 shows how transaction costs in the market changed over time with increasing experience. The market experience is defined as the number of experiment sessions executed with the number of potential participants drawn from a limited pool of bidders. We could have defined this using individual experience; however, the relationship between individual experience and market experience is a subjective one. It can be argued that the market is as experienced as the most experienced players since they will be using the most advanced strategies that will lead the changes in the market. The decisions that inexperienced players make on average will not provide useful feedback to other participants. The fact that the participants are selected from a limited pool of 38 individuals combined with observations from the qualitative data collected supports the assertion that knowledge was carried forward to future bidding sessions. Hence each session is more experienced than the previous one.

The total transaction cost in the market includes the cost for contractors not paid to the subcontractors as well as the costs for subcontractors that are not related to the project. For the contractor, the transaction cost depends on the subcontractor selection strategy since it consists of the collaboration cost, bid request cost and bid evaluation cost. Repeated business with the same subcontractor will minimize the collaboration cost. The other two costs are related to how confident the contractor is about the price they receive from the subcontractor. By decreasing search efforts for 


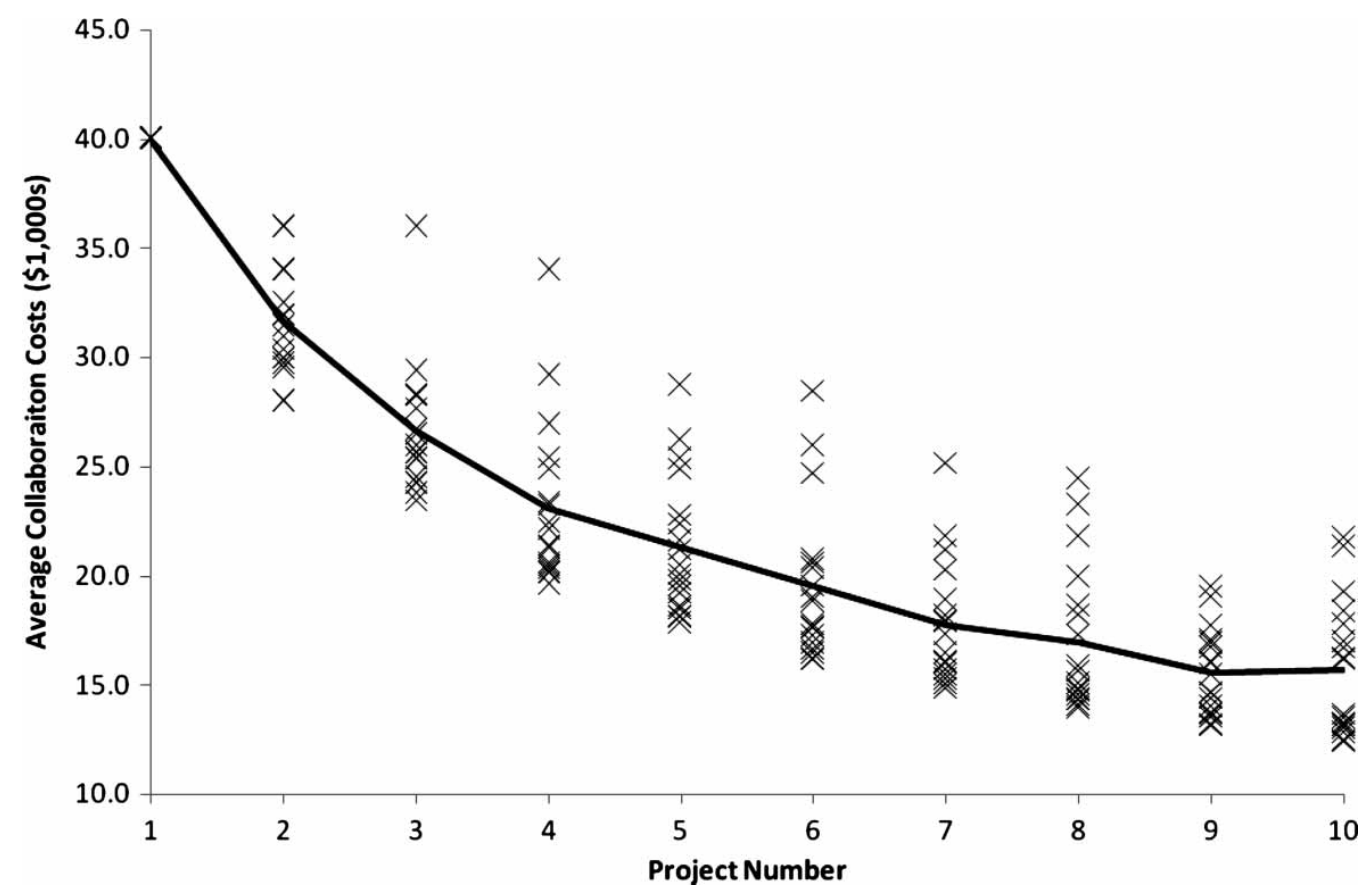

Figure 1 Average collaboration cost for each project across 18 experiments

subcontractors and bid evaluation costs, the contractors can minimize these costs. Although bid preparation cost is relatively small compared with other transaction costs, it is also determined by the partnering strategy employed. By submitting bids on projects where there is a high probability of winning, the subcontractors can minimize their transaction costs. Since the partnering strategy is the only determinant of the transaction cost of the market, we describe the trend in Figure 3 as being associated with partnering strategies. A second degree parabola is fitted to the transaction cost data in order to show the trend of the change.

\section{Discussion}

The first goal of this paper was to investigate whether bidders in a simulated market would behave opportunistically. In Hypothesis 1, we established that, as collaboration costs decreased over time as a consequence of repeated transactions, the average winning bid price in the market increased. In order to examine the relationship between these two trends, we examined the specific strategies employed by the participants. At the end of each experiment session, participants were asked to explain the strategy they implemented. This allowed us to examine if the price changes were the result of an intentional strategy. As subcontractors were awarded bids they realized that they had an advantage over other subcontractors. Realizing this, they began submitting higher bids that captured more of the economic benefits created by reductions in collaboration costs. We found that opportunistic behaviour did emerge in this bidding experiment where there were costs for contractors to switch to another subcontractor across repetitive projects. Below is a typical response that explains the relationship between decreasing collaboration cost and increasing market price:

Subcontractor 11/Experiment 10: In the first round I took a loss on purpose to win a contract, so that in the second round my collaborative cost would be low compared to the other subs. That way I would have a significant advantage in future rounds of winning contracts because of my much lower collaborative cost for the contractor. Then, I just made sure my bids were as high as possible, while being lower than the project cost + collaborative cost for other subs.

The following response by a contractor further supports this point and describes how opportunistic behaviour emerged:

Contractor 3/Experiment 12: I used [Subcontractor 9] consistently for around five [projects] and was being successful until I noticed he was jacking up prices as the collaboration costs had been lowering... I attempted to convey a message to him by not requesting a price from him for one round, and 


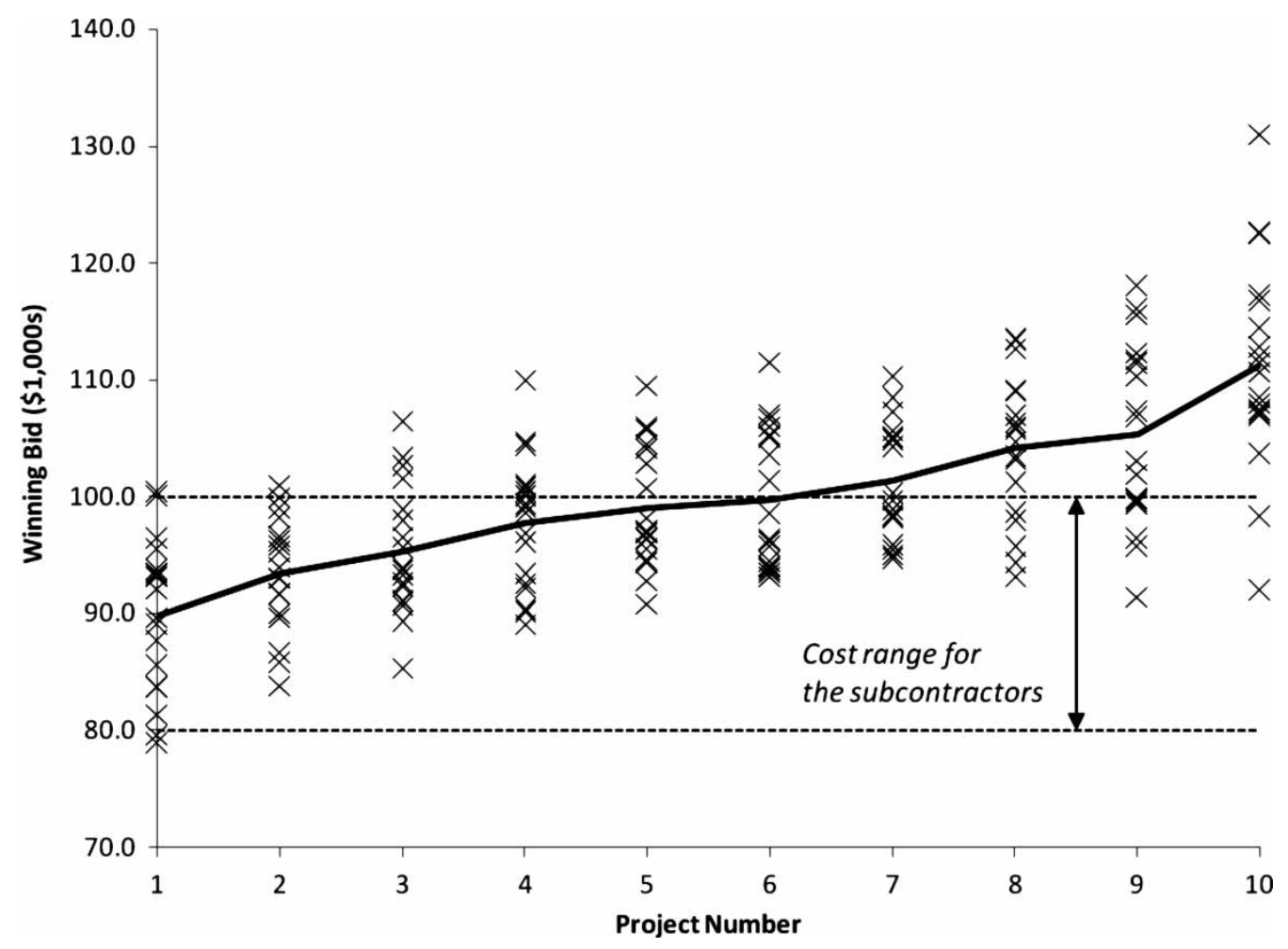

Figure 2 Average winning bid price for each project across 18 experiments

instead requesting prices from other people. I figured either someone else would give me a more reasonable price, or he would get the message and send me a price anyway, while lowering his profit margin. Instead, I got no price offers at all. I tried unsuccessfully to switch my main subcontractor, but no other subcontractor would give me a price because the game was so many rounds in. [Subcontractor 9's] strategy worked amazingly and I was forced to accept his high prices in order to maintain even the lowest profit. My profit, even though my collaboration costs were low, wound up being less than it was at the beginning. In the last turn, I finally got an offer from [Subcontractor 3], but by then the damage had been done and I was at the bottom of the pack.
The quote above establishes the relationship between decreasing collaboration costs over time and increasing bidding prices. The increasing winning bid prices were the result of intentional bidding strategies by the subcontractors. Therefore we propose the following proposition:

PROPOSITION 1: Opportunistic behaviour emerges as parties become more dependent on each other in task interdependent project networks where there is incentive for continuous collaboration. This opportunistic behaviour can be classified as a form of the hold-up problem.

The existence of opportunistic behaviour has implications at the network level. The second research question of this study was to observe how the existence of the hold-up threat affects the efficiency of the overall market. Market efficiency in this case is a measure

Table 1 Comparison of winning bid prices by using three-period lag

\begin{tabular}{lccccccc}
\hline & $\begin{array}{c}\text { Project } 1 \text { vs. } \\
\text { Project } 4\end{array}$ & $\begin{array}{c}\text { Project } 2 \text { vs. } \\
\text { Project } 5\end{array}$ & $\begin{array}{c}\text { Project } 3 \text { vs. } \\
\text { Project } 6\end{array}$ & $\begin{array}{c}\text { Project } 4 \text { vs. } \\
\text { Project } 7\end{array}$ & $\begin{array}{c}\text { Project } 5 \text { vs. } \\
\text { Project } 8\end{array}$ & $\begin{array}{c}\text { Project } 6 \text { vs. } \\
\text { Project } 9\end{array}$ & $\begin{array}{c}\text { Project } 7 \text { vs. } \\
\text { Project } 10\end{array}$ \\
\hline$p$-value & $0.000^{* * *}$ & $0.001^{* * *}$ & $0.013^{*}$ & $0.023^{*}$ & $0.007^{* *}$ & $0.011^{*}$ & $0.000^{* * *}$ \\
\hline
\end{tabular}

${ }^{*} p<0.05$.

${ }^{* *} p<0.01$

$* * * p<0.001$. 


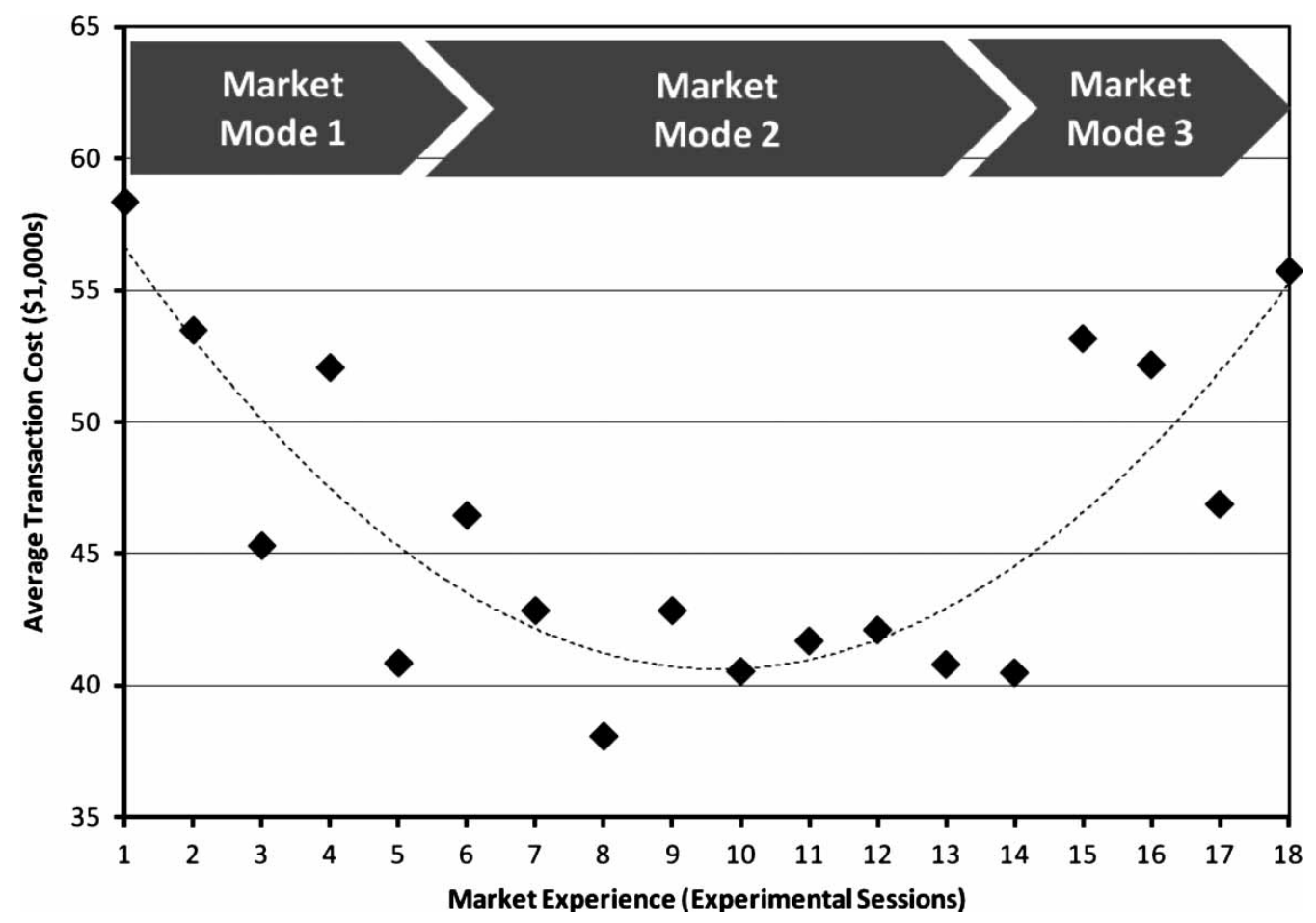

Figure 3 Evolution of the efficiency of the market over time

that articulates the interactional costs between contractors and subcontractors associated with the transaction. We graphed the evolution of the market efficiency in terms of average transaction costs in Figure 3. The responses by the participants will provide insight into the dynamics behind this evolution. Examination of these responses together with the empirical data collected resulted in three distinct market evolution modes to be discussed in the following sections.

\section{Market evolution mode 1: realization of the benefits of close collaboration and emergence of partnering}

At the market level, we demonstrated that the efficiency of the market in terms of transaction costs improves initially as contractors and subcontractors gain experience working together. This resulted in reduced collaboration costs. In the first few projects when participants were inexperienced, the common approach by the subcontractors was to employ a cost-plus strategy and the approach by contractors was to request bids from several subcontractors and try to pick the one that provided the highest profit. Subcontractors who were fortunate enough to get low bids in the initial few rounds ended up making higher profits. With increasing experience, contractors realized that the strategy of sticking with one subcontractor minimized the transaction costs and therefore maximized profit. The following quote by Contractor 6 from Experiment 1 illustrates this point:

Contractor 6/Experiment 1: It's best for both the [contractor] and the [subcontractor] if a stable longterm relationship is developed. Then we don't have to waste money on bids or bid requests that don't get accepted.

\section{Market evolution mode 2: efficient but unstable equilibrium}

When long-term partnerships developed, the market reached an optimum point where the transaction costs were minimized. However at this point, since the transaction cost decreases by this point were marginal, the bidding transaction evolved into a zero-sum game. There is a gain from the collaboration, but the distribution of the gains is yet to be determined. Some subcontractors realized that they can get more of the benefit by following an opportunistic strategy. They figured that by bidding at a loss for several projects they can be more than compensated by future earnings if they could lock in a contractor. As a consequence, the bids became very low with the expectation of future benefits. This is similar to the case in the industry when subcontractors bid low to 
become a qualified supplier and earn future work. But when all participants in the experiment (or subcontractors in the industry) realized with experience that this was the best strategy, it became commonplace in the market. As improvements in collaboration costs diminished, the opportunistic behaviour drove the market away from the unstable equilibrium point. The following quote by Subcontractor 10 from Experiment 11 illustrates how subcontractors adjusted their strategies to be able to survive in the market:

Subcontractor 10/Experiment 11: A couple other players this time ran at a significant deficit, and went for large profits the last few rounds. While I don't really like this strategy, I am curious to modify my own strategy to one closer to this. i.e., take a few more risks earlier on, and go for slightly larger profits after the midpoint of the game.

\section{Market evolution mode 3: self-protection strategies erode partnerships and market efficiency}

Opportunistic behaviour by the subcontractors forced the contractors to begin to protect themselves by switching subcontractors from project to project in order to increase their options and to signal to their dominant subcontractor that they can select other subcontractors for the work. Below is an example of how a contractor was forced to increase the number of subcontractors with whom they worked:

Contractor 9/Experiment 16: In mid game, I tried to change which subcontractor I utilized but I did not receive any bids from any that I requested, so I had to stay with the same subcontractor. This hurt me as the subcontractor I was left to select was not turning out to be the most profitable for me. By the 8th [project], I was finally getting competitive bids from other subcontractors but they still were not as competitive in pricing as the one I was selecting... Perhaps soliciting 2 or 3 bids each turn might have turned out a better outcome.

After a period of mutual adjustment, the market is back to the transaction cost levels where it started and contractors selecting from a pool of two to three subcontractors. This is an example of how the market does the iteration on behalf of individuals for whom computational capacity is limited. If a group of inexperienced people can respond to a market and develop survival strategies across 10 projects and, in the case of repeat participants, across 18 experiment sessions, it is reasonable to assume that industry professionals with years of experience will respond similarly in the existence of threat of opportunism. The quotes from the participants above show how individuals learn from not only their experience but also by receiving feedback from the market. As a result, the successful bidding strategies by subcontractors and procurement strategies by contractors were copied by others and became the market norm. The change in the common behaviour can be argued as the underlying reason behind the change in transaction costs in the market. Therefore, based on the discussion above we propose the following proposition:

PROPOSITION 2: The emergence of opportunistic behaviour affects the market efficiency. Although the opportunistic behaviour is not always apparent in the market, the threat of it impacts subcontractor selection strategies and, as a result, impacts the overall efficiency of the market. Therefore hold-up in repeated transactions is not only a wealth distribution problem, but also a market efficiency problem.

Preventing opportunism is a more challenging problem than defining it. For a single project, the natural reaction for self-protection is to attempt to write more powerful contracts and facilitate conflict resolution processes. However, this is practically infeasible due to the complexity of construction projects and, according to some researchers, limits the flexibility of the project (Chang and Ive, 2007a). Boukendour (2007) proposed an innovative method of procurement where the clients are given an option to switch from lump sum contract to cost-plus contract which alters the incentive system and limits the opportunistic behaviour of the contractor. The case for repetitive projects is more complicated. Writing contracts that will limit the opportunistic behaviour in repetitive transactions is extremely difficult if not impracticable. While academicians and experts propose companies and seek long-term partnership, the underlying assumption is that the industry is in market evolution mode 1 from Figure 3 and that economies will be afforded to companies that partner with each other more and evolve to market evolution mode 2 . However, the industry has significant bidding experience and the firms already have the market experience required to be in market evolution mode 3 . Although it is true that the optimum efficiency of the market is where there are long-term partnerships (market evolution mode 2), the method of reaching the middle of the curve is different for those two points. Optimization by individual firms moves the market to the right. This makes market modes 1 and 2 unstable and therefore the shift of the market to the right is a natural consequence. 


\section{Limitations}

The experimental method used in this study has several limitations. The experiment is designed only to demonstrate and observe the macro-level impacts of opportunistic behaviour. The bidding and subcontracting decisions in real life are much more complicated than modelled here. Many factors interact when making these decisions; such as the quality or reputation of the subcontractor and specifications of the work, financial stability, current workload and technical expertise, among other factors (Russell et al., 1990). We simplified the subcontracting process so that it included all the dynamics relevant to opportunistic behaviour within a limited number of projects upon which to bid. One advantage of simplifying the game is that the participants could make more thorough evaluations before making decisions. We also argued how the opportunistic behaviour might force project networks to move away from the optimal relationally stable structure. However, we only included exploitation learning (March, 1991) which relates to utilization of existing resources as opposed to exploration learning which relates to investing in new knowledge. For example, in the experiment no innovations are created that may affect efficiency and price asymmetrically across the participants. From that viewpoint, there is strong incentive to subcontract with the same subcontractor since the contractor would like to get most out of each single investment. However, one incentive to keep a pool of several subcontractors is to have access to new knowledge and new approaches that exist in the market. Exploration may also be a strong determinant of market efficiency and should be included in future research on this topic. Another factor that may impact these findings is the national market economy in which the experiment is conducted. Research has shown that different market economies are predisposed to different contractual and partnering approaches (Hall and Soskice, 2001; Korkmaz and Messner, 2008). Future research should examine the extent to which these findings apply to other market economies, particularly given the extent to which the $\mathrm{A} / \mathrm{E} / \mathrm{C}$ industry has globalized over the past two decades.

\section{Conclusion}

Past research has demonstrated analytically that subcontractor selection decisions made by a contractor may have an adverse impact on revenue if the potential for hold-up is disregarded when there are incentives for continuous collaboration. We developed an online interactive bidding marketplace and conducted a series of experiments to examine empirically whether such opportunistic behaviour would emerge across repetitive transactions between contractors and subcontractors. We then investigated the impact that the emergence of opportunistic behaviour would have on the overall market efficiency over time. We conducted a total of 18 experiments involving 6947 competitive bidding transactions between contractors and a pool of subcontractors in a simulated subcontracting process. The 38 participants in the experiment were recruited from AMT, an online workplace website. By encouraging participants to participate in multiple bidding experiments, we were able to observe how the market evolved as participants became more experienced.

We found that opportunistic behaviour did emerge in the bidding experiments. We also showed through repeated transactions that the market iteratively evolves towards the Nash Equilibrium point. Upon reaching the equilibrium point, the contractors followed a self-protection strategy which increased the total transaction costs and therefore decreased the efficiency of the market. Although it is not visible at the equilibrium point, opportunistic behaviour is the driving force behind the evolution of the market to an inefficient point in terms of total transaction costs. This research also aimed to explore the relationship between strategic decisions by individuals and macro-level market behaviour. We showed how profit-maximizing behaviour does not necessarily lead to the optimal outcome for the market.

Although the intention here is not to propose an optimum strategy, it is reasonable to pose the question of optimality. Future research should focus on the question of aligning the firm-level incentives with industry level optimal outcomes. An additional component to the bidding experiment or a change in the structure can turn long-term partnerships to a natural outcome and therefore increase the overall productivity of the industry. That way we can count on the natural evolution instead of an expectation of goodwill behaviour in order to improve productivity.

\section{Acknowledgments}

This material is based in part upon work supported by the National Science Foundation under Grant No. 0729253 and an Alfred P. Sloan Foundation Industry Studies Fellowship. Any opinions, findings and conclusions or recommendations expressed in this material are those of the authors and do not necessarily reflect the views of the National Science Foundation or the Alfred P. Sloan Foundation.

\section{References}

Aghion P., Dewatripont M. and Rey P. (1994) Renegotiation design with unverifiable information. Econometrica, 62(2), 257-82. 
Barlow J. (2000) Innovation and learning in complex offshore construction projects. Research Policy, 29(7-8), 973-89.

Boukendour S. (2007) Preventing post-contractual opportunism by an option to switch from one contract to another. Construction Management and Economics, 25(7), 723-7.

Camerer C. (2003) Behavioural Game Theory: Experiments in Strategic Interaction, Princeton University Press, Princeton, NJ.

Castaneda M. (2006) The hold-up problem in a repeated relationship. International fournal of Industrial Organization, 24(5), 953-70.

Chan A., Chan D., Chiang Y., Tang B., Chan E. and Ho K. (2004) Exploring critical success factors for partnering in construction projects. Fournal of Construction Engineering and Management, 130(2), 188-98.

Chang C.Y. and Ive G. (2007a) Reversal of bargaining power in construction projects: meaning, existence and implications. Construction Management and Economics, 25(8), 845-55.

Chang C.Y. and Ive G. (2007b) The hold-up problem in the management of construction projects: a case study of the channel tunnel. International fournal of Project Management, 25(4), 394-404.

Construction Industry Institute (CII) (1991) "In search of partnering excellence." Special Publication No. 17-1, Report, Partnering Task Force of CII, Austin, Tex

DeVilbiss C.E. and Leonard P. (2000) Partnering is the foundation of a learning organization. Fournal of Management in Engineering, 16(4), 47-57.

Eccles R. (1981) The quasifirm in the construction industry. fournal of Economic Behaviour and Organization, 2(4), 335-57.

Goldberg V. (1976) Regulation and administered contracts. The Bell Fournal of Economics, 7(12), 426-48.

Hall P. and Soskice D. (2001) Varieties of Capitalism: The Institutional Foundations of Comparative Advantage, Oxford University Press, New York.

Henrich J. (2000) Does culture matter in economic behaviour? Ultimatum game bargaining among the Machiguenga of the Peruvian Amazon. The American Economic Review, 90(4), 973-9.

Ho S. and Liu L. (2004) An analytical model for analyzing construction claims and opportunistic bidding. Fournal of Construction Engineering and Management, 130(1), 94-104.

Holt G. (1998) Which contractor selection methodology?. International fournal of Project Management, 16(3), 153-64.

Kittur A., Chi E. and Suh B. (2008) Crowdsourcing user studies with Mechanical Turk, Proceedings of the twentysixth annual SIGCHI conference on Human factors in computing systems, ACM, Florence, Italy, pp. 453-53.
Klein B., Crawford R. and Alchian A. (1978) Vertical integration, appropriable rents, and the competitive contracting process. Fournal of Law and Economics, 21(2), 297-326.

Korkmaz S. and Messner J. (2008) Competitive positioning and continuity of construction firms in international markets. Fournal of Management in Engineering, 24(4), 207-16.

Kumaraswamy M. and Matthews J. (2000) Improved subcontractor selection employing partnering principles. Fournal of Management in Engineering, 16(3), 47-57.

Lo W., Lin C.L. and Yan M.R. (2007) Contractor's opportunistic bidding behaviour and equilibrium price level in the construction market. Fournal of Construction Engineering and Management, 133(6), 409-16.

March J. (1991) Exploration and exploitation in organization learning. Organization Science, 2(1), 71-87.

Mailath G.J. (1998) Do people play Nash equilibrium? Lessons from evolutionary game theory. Fournal of Economic Literature, 36, 1347-74.

Miozzo M. and Dewick P. (2004) Networks and innovation in European construction: benefits from inter-organisational cooperation in a fragmented industry. International fournal of Technology Management, 27(1), 68-92.

Nash J. (1951) Non-cooperative games. The Annals of Mathematics, 54(2), 286-95.

Noldeke G. and Schmidt K.M. (1995) Option contracts and renegotiation - a solution to the hold-up problem. $R A N D$ Fournal of Economics, 26(2), 163-79.

Pitchford R. and Snyder C.M. (2004) A solution to the holdup problem involving gradual investment. Fournal of Economic Theory, 114(1), 88-103.

Provan K.G. and Skinner S.J. (1989) Interorganizational dependence and control as predictors of opportunism in dealer-supplier relations. The Academy of Management Fournal, 32(1), 202-12.

Rogerson W. (1992) Contractual solutions to the hold-up problem. Review of Economic Studies, 59, 777-94.

Russell J., Skibniewski M. and Cozier D. (1990) Qualifier-2: knowledge-based system for contractor prequalification. Fournal of Construction Engineering and Management, 116 (1), 157-71.

Taylor J., Levitt R. and Villarroel A. (2009) Simulating learning dynamics in project networks. Fournal of Construction Engineering and Management, 135(10), 1009-15.

Unsal, H.I. and Taylor, J.E. (2011) Modeling inter-firm dependency: a game theoretic simulation to examine the hold-up problem in project networks. Fournal of Construction Engineering and Management, 137(4), 284-293.

Williamson O. (1975) Markets and Hierarchies, MacMillan, New York. 